\title{
Analysis of Variation of Stiffness Derivative With Mach Number and Angle of Attack for a Supersonic Flow
}

\author{
Asha Crasta ${ }^{1}$, Aysha Shabana, ${ }^{2}$ Renita Monis ${ }^{3}$, S.A.Khan ${ }^{4}$ \\ 1. Associate Professor, Department of Mathematics, M.I.T.E, Moodabidri, Karnataka, India. \\ 2, 3. Research Scholar, Department of Mathematics, M.I.T.E, Moodabidri, Karnataka, India. \\ 4. Professor, Mechanical Engineering Department, Faculty of Engineering, IIUM, Kuala Lumpur, Malaysia.
}

\begin{abstract}
In this paper unified supersonic theory is used to derive the expressions of Stiffness derivative of a wedge in Hypersonic flow. This paper demonstrates the effects of pivot position on the stffness derivative with Mach number and incidence angle. From the above discussion it is seen that behaviour of the stiffness derivative is the same for $h=0$ to 0.4 and also for $h=0.8,0.9$, and 1.0. Due to the pivot position variations there is a significant variation of Stiffness derivative with Mach number and incidence angle.
\end{abstract}

Keywords: Incidence angle, Stiffness derivative, Supersonic flow, variation

\section{Introduction}

Ghosh and Mistry [2] have given a theory for the quasi steady flow over the oscillating 2-D wedge which has been further extended by Ghosh [3] to solve the axi-symmetric flow problem. Crasta and khan [4 to 28] have taken Ghosh's [1] large deflection similitude into consideration to develop an unsteady piston theory for the prediction of stability derivatives of oscillating planar and non-planar wedges. Here an attempt is made to analyze the stiffness derivative variation with Mach number and incidence angle for various pivot position from $\mathrm{h}=0$ to 1 .

\section{Analysis}

The exact expression for pressure ratio using the second order shock wave expansion theory, can be written in quadratic form in pressure ratio since the piston Mach number $\mathrm{M}_{\mathrm{p}}=\mathrm{u}_{\mathrm{p}} / \mathrm{a}_{\infty} \gg 1$, yielding :

$\frac{p}{p_{\infty}}=1+A M_{\infty}^{2} \sin ^{2} \alpha+A M_{\infty} \sin \alpha \sqrt{B+M_{\infty}^{2} \sin ^{2} \alpha}$

A piston theory which has been used in equation (1) has been extended to supersonic flow. The expression is given below:

$\frac{p}{p_{\infty}}=1+A\left(\frac{M_{p}}{\cos \phi}\right)^{2}+A\left(\frac{M_{p}}{\cos \phi}\right)\left(B+\left(\frac{M_{p}}{\cos \phi}\right)^{2}\right)^{\frac{1}{2}}$

Where $p_{\infty}$ is free stream pressure, $A=\frac{(\gamma+1)}{4}, B=\left(4 /(\gamma+1)^{2}, \gamma\right.$ is the specific heat ratio and $M_{p}=$ the local piston Mach number normal to the wedge surface.

The nose down moment is given by:

$$
-m=\int_{0}^{L}\left(x-x_{\circ}\right) p d x
$$

The stiffness derivatives is given by:

$$
-C_{m_{\alpha_{\circ}}}=\frac{1}{\frac{1}{2} \rho_{\infty} U_{\infty}{ }^{2} L^{2}}\left(-\frac{\partial m}{\partial \alpha_{\circ}}\right)
$$

Evaluated at $\quad \alpha=\alpha_{0}$ and $\mathrm{q}=0$, Piston Mach number

$M_{p}=\frac{1}{a_{\infty}}\left[U_{\infty} \operatorname{Sin}^{2} \alpha+\left(x-x_{o}\right) \mathrm{q}\right]$

Defining $\mathrm{x}_{0}=\mathrm{hL} \cos ^{2} \propto_{0}, \mathrm{c}=\mathrm{L} \cos \propto_{0}, S_{1}^{1}=\frac{M_{\infty} \sin \alpha_{O}}{\cos \varphi}$, the stiffness derivative of a wedge becomes

$-\mathrm{C}_{\mathrm{m}_{\alpha}}=\left[\frac{(\mathrm{\gamma}+1)}{\mathrm{M}_{\infty} \cos \alpha \circ \cos \varnothing}\right] \mathrm{F}\left(\mathrm{S}^{1}{ }_{1}\right)\left(\frac{1}{2}-\mathrm{h}^{2} \cos ^{2} \alpha_{\circ}\right)$

Where 
$F\left(S^{1}{ }_{1}\right)=2 S^{1}{ }_{1}+\frac{B+2 S^{1}{ }_{1}{ }^{2}}{\sqrt{B+S^{1}{ }_{1}{ }^{2}}}$

Graphs have been plotted for Stiffness derivative versus Mach number and incidence angle for variant pivot positions and results have been discussed.

\section{Results And Discussion}

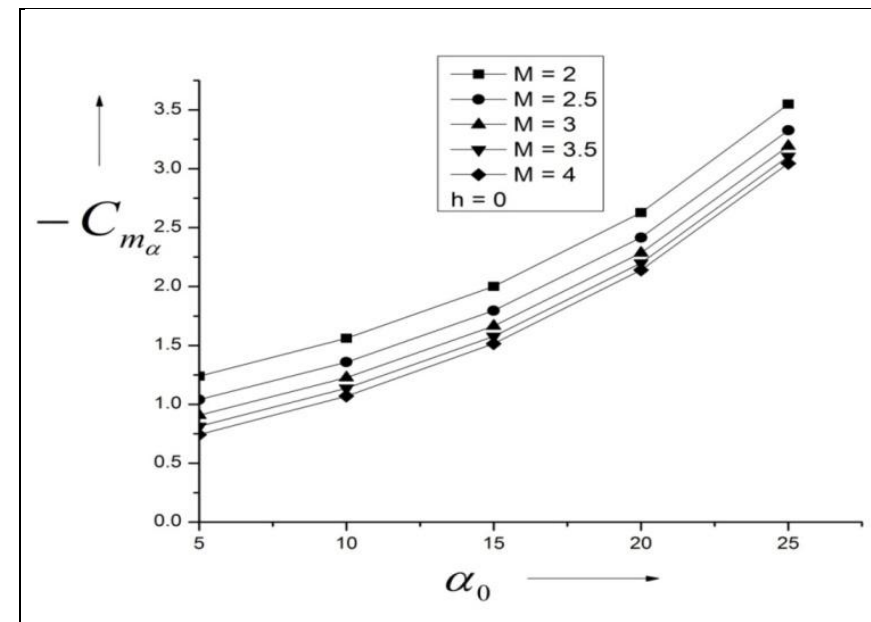

Fig1: Stiffness derivative versus incidence angle for pivot position $\mathrm{h}=0$

Examination of Fig.1 shows the enhancement of stiffness derivative with incidence angle. Futher there is decrement in Stiffness derivative with Mach number as the stiffness derivative is considered at the nose of the wedge i.e. at $\mathrm{h}=0$. The value of Stiffness derivative ranges between 1.25 to 0.75 for angle of attack of 5 degrees as Mach number increases from $M=2$ to $M=4$ there is continous decrement in the stiffness derivatives as the inertia terms as the Mach number is in the denominator of the expression. Also, due to the variation in the pressure distribution on the surface of the wedge.

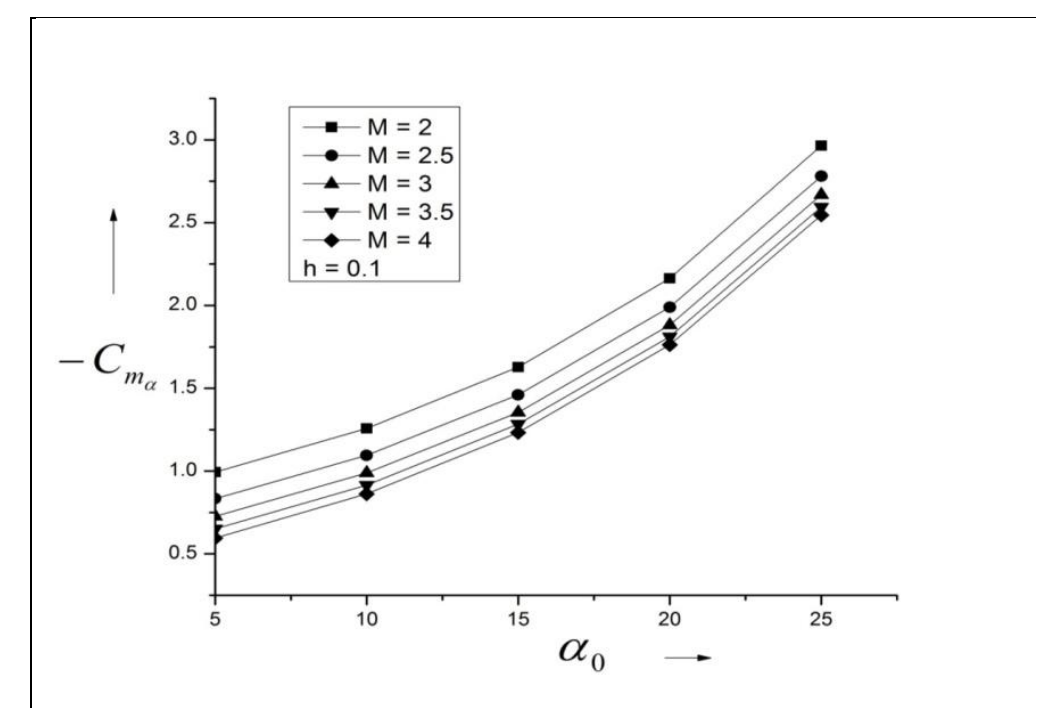

Fig2: Stiffness derivative versus incidence angle for pivot position $\mathrm{h}=0.1$

In Fig.2, the pivot position is shifted to $\mathrm{h}=0.1$. It is evident as the pivot position moves from the nose, the Stiffness derivative decreases futher with the increase in the Mach number and incidence angle. Even though the Stiffness derivative incrases with incidence angle and decrease with Mach number it is seen that the range of value is reduced when compared to that at the nose, this trend due to the shift in the plan form area of the wedge. 


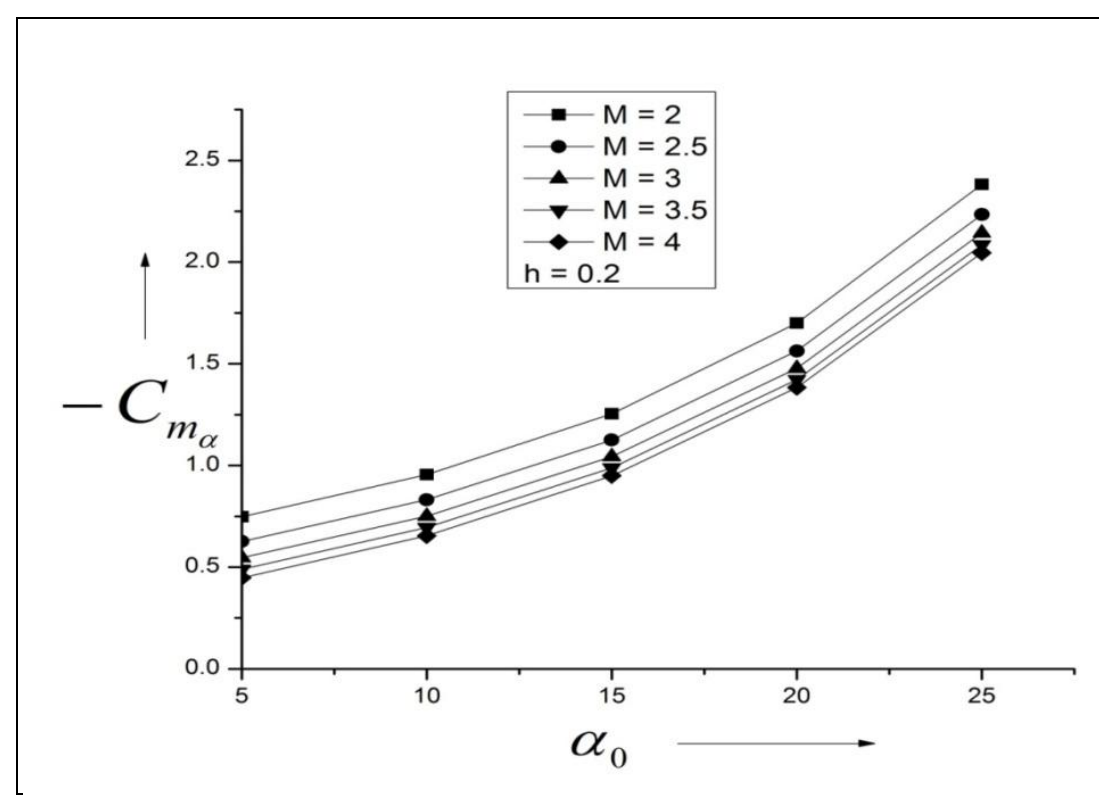

Fig3: Stiffness derivative versus incidence angle for pivot position $h=0.2$

Fig. 3 represents the Stiffness derivative variation with incidence angle for pivot position $\mathrm{h}=0.2$. From the figure it seen that there is significant decrease in the value of Stiffness derivative for incidence angle 5 degrees and Mach number $\mathrm{M}=2$ is visible and in the proportion the trend continues and the reasons for this trend holds as discuss earlier.

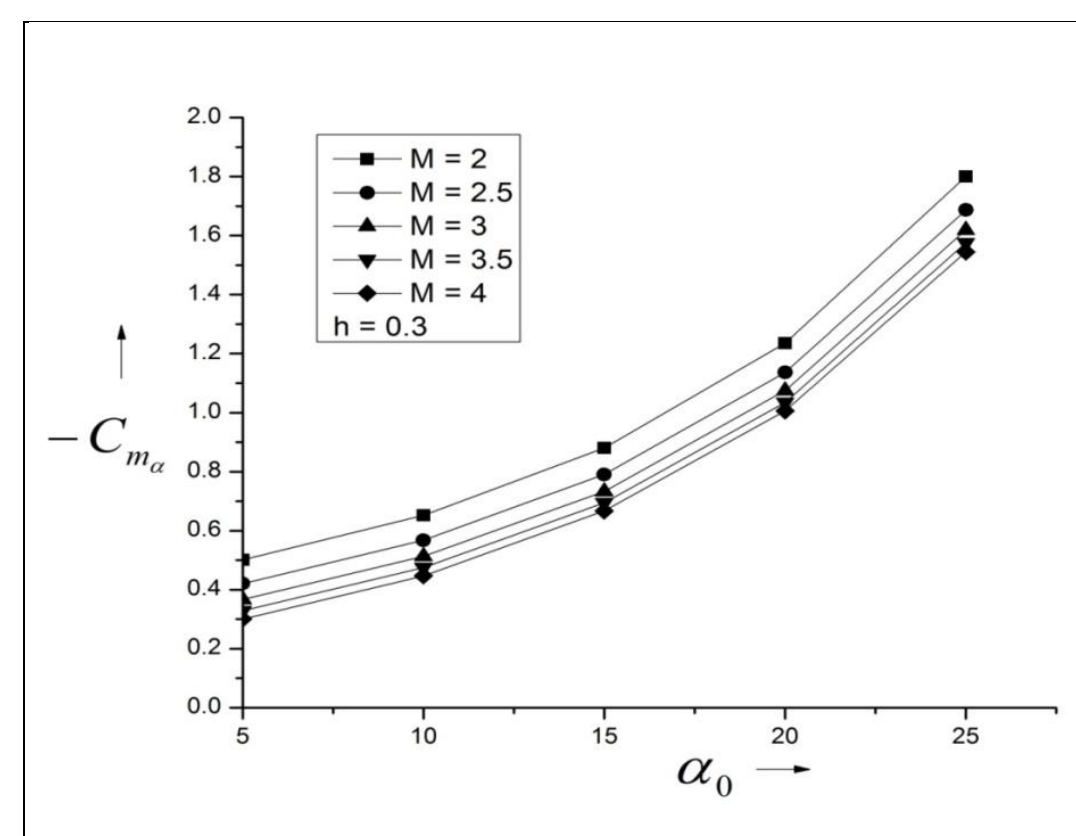

Fig.4: Stiffness derivative versus incidence angle for pivot position $\mathrm{h}=0.3$

Fig.4 shows the stiffness derivative variation with the incidence angle for pivot position $h=0.3$. Here once again it is seen that there further decrement in the values of the stiffness derivatives due to the continous decrease of the plan form area. 


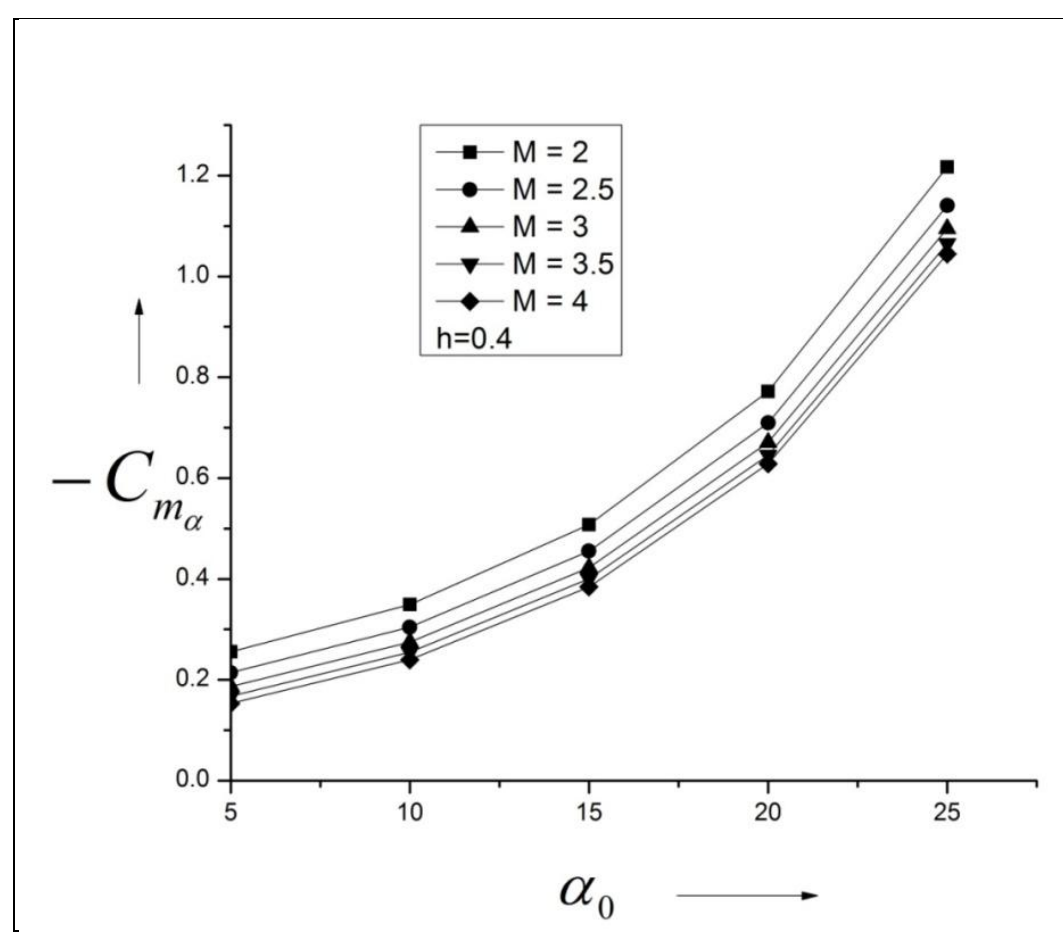

Fig.5: Stiffness derivative versus incidence angle for pivot position $\mathrm{h}=0.4$

Fig. 5 presents the results of Stiffness derivative with incidence angle for pivot $h=0.4$. At incidence angle 5 degrees there is further decrease in the value of Stiffness derivative when the pivot position moves from leading edge to the trailing edge and the same reason is valid as discussed earlier.

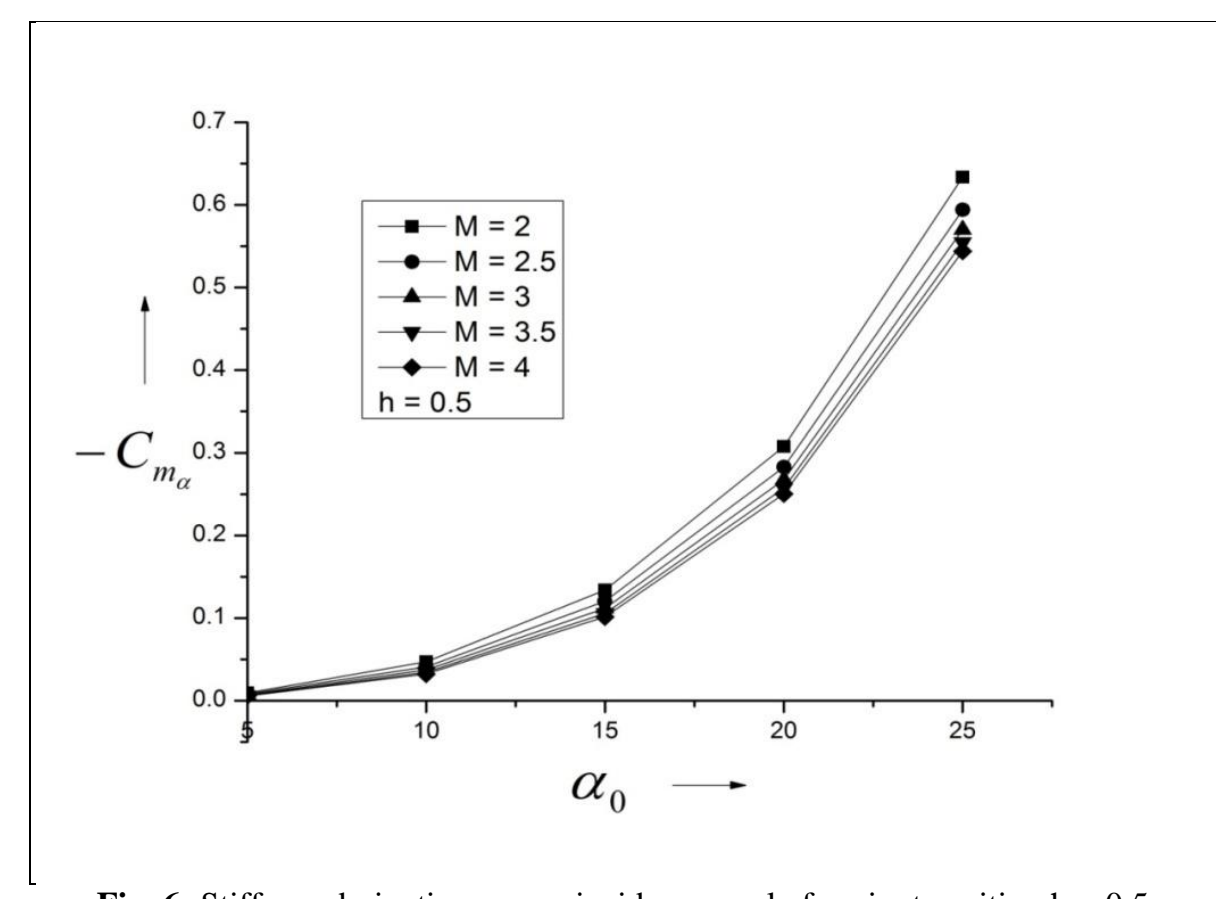

Fig. 6: Stiffness derivative versus incidence angle for pivot position $\mathrm{h}=0.5$

In Fig.6 it is clearly visible that there is no much difference in Stiffness derivative and incidence angle 5 to 10 degrees since the pivot position $\mathrm{h}=0.5$ is very close to the aerodynamic center of pressure. It is seen that as we are progressively moving from leading edge $h=0$ towards trailing edge $h=1$, there is a continuous decrease in the plan form area of the wedge resulting in change of surface pressure and hence the variations in the stiffness derivative. 


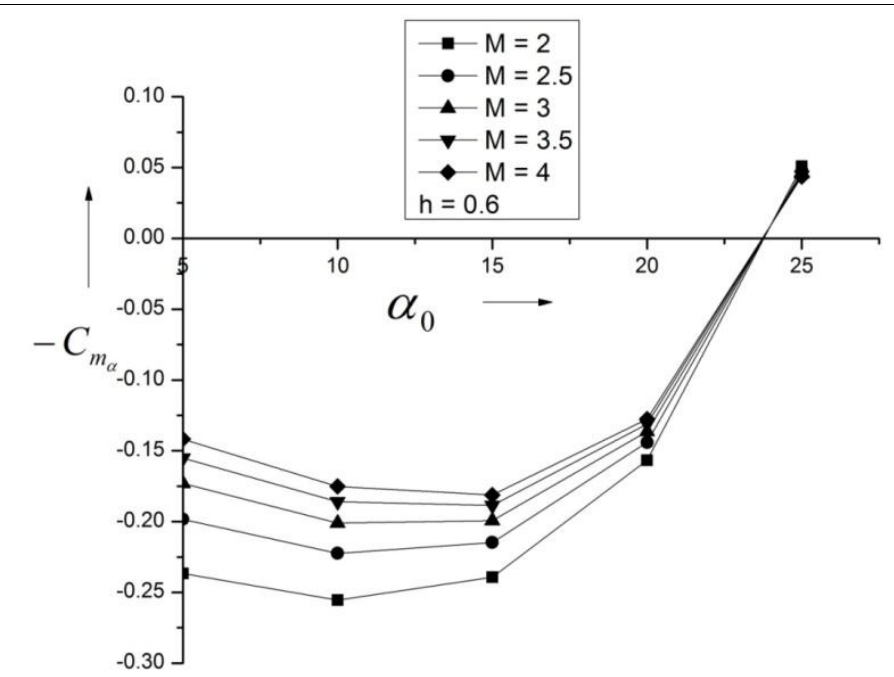

Fig.7: Stiffness derivative versus incidence angle for pivot position $\mathrm{h}=0.6$

Fig.7 shows the Stiffness derivative variation with the incidence angle for pivot position $\mathrm{h}=0.6$. A different behavior is observed. This trend is due to location of pivot position which is beyond the center of pressure and more so due to the shift of the larger area towards the leading edge and the plan form area available to balance the negative static margin is not available, however at angle of incidence of 23 degrees and above there a shift in the center of pressure and hence in the sign of the stiffness derivative.

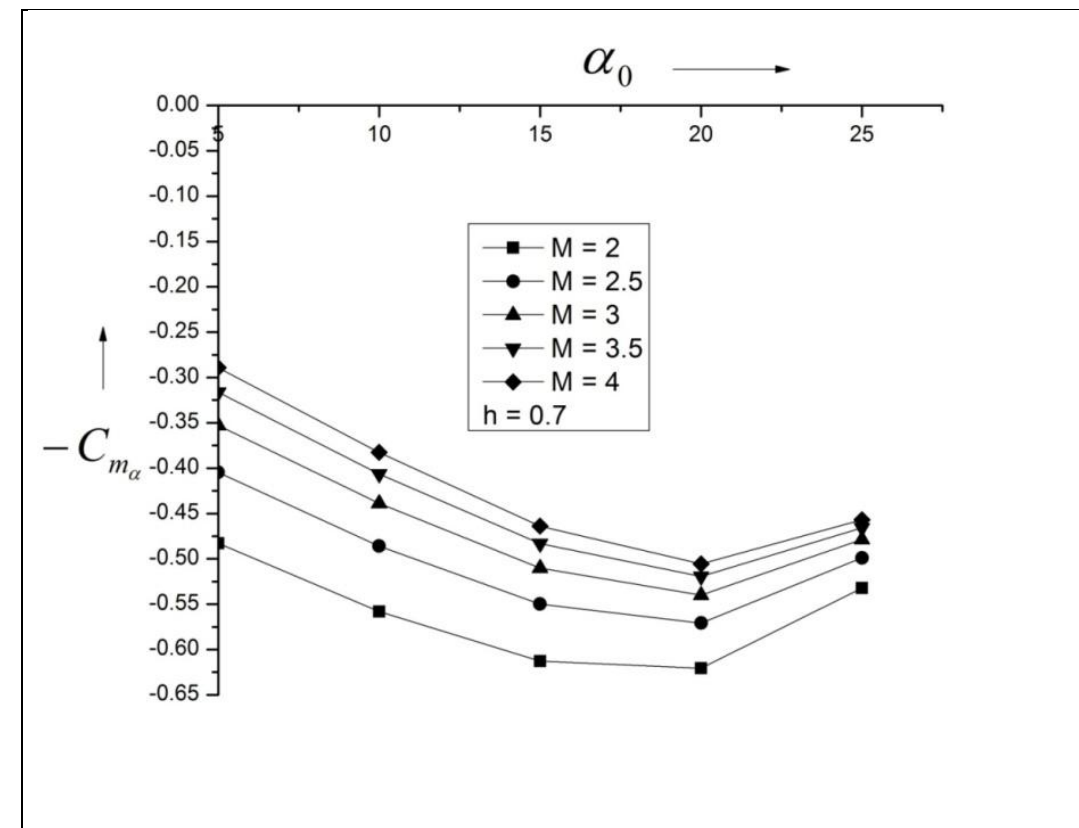

Fig. 8: Stiffness derivative versus incidence angle for pivot position $h=0.7$

Fig. 8 shows the Stiffness derivative variation with incidence angle for pivot position $\mathrm{h}=0.7$ from the nose. The value of stiffness derivative decreases as the Mach number increases and reduces with the angle of attack. This trend is due to the major shift in the pan form area, location of the pivot position which behind the center of pressure and under these circumstances when stiffness derivatives are evaluated they have large negative values as compared to the lower values of the pivot position and with increase in angle of attack flow field is such that even incidence angle is unable to give any relief. Normally angle of attack has been used to stabilize the flying objects. This is possible when we consider the body as whole and not a section of the moving vehicle. 


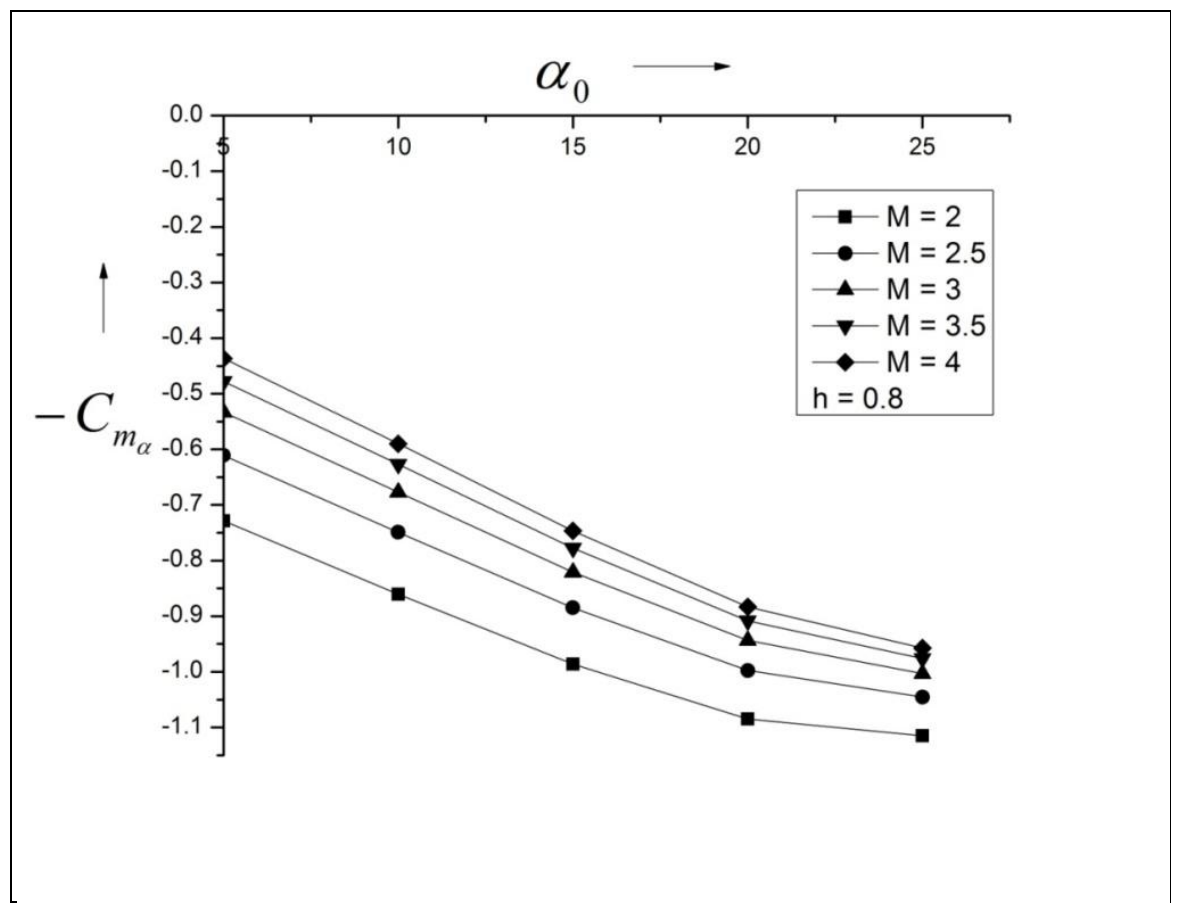

Fig. 9: Stiffness derivative versus incidence ange for pivot position $h=0.8$

Fig.9 shows the stiffness derivative variation with angle of incidence for pivot $\mathrm{h}=0.8$. From the figure it is seen that there a linear decrement in stiffness derivative with respect to incidence angle. The range of values for stiffness derivative has further gone down negative, and reasons for this trend holds as discussed above.

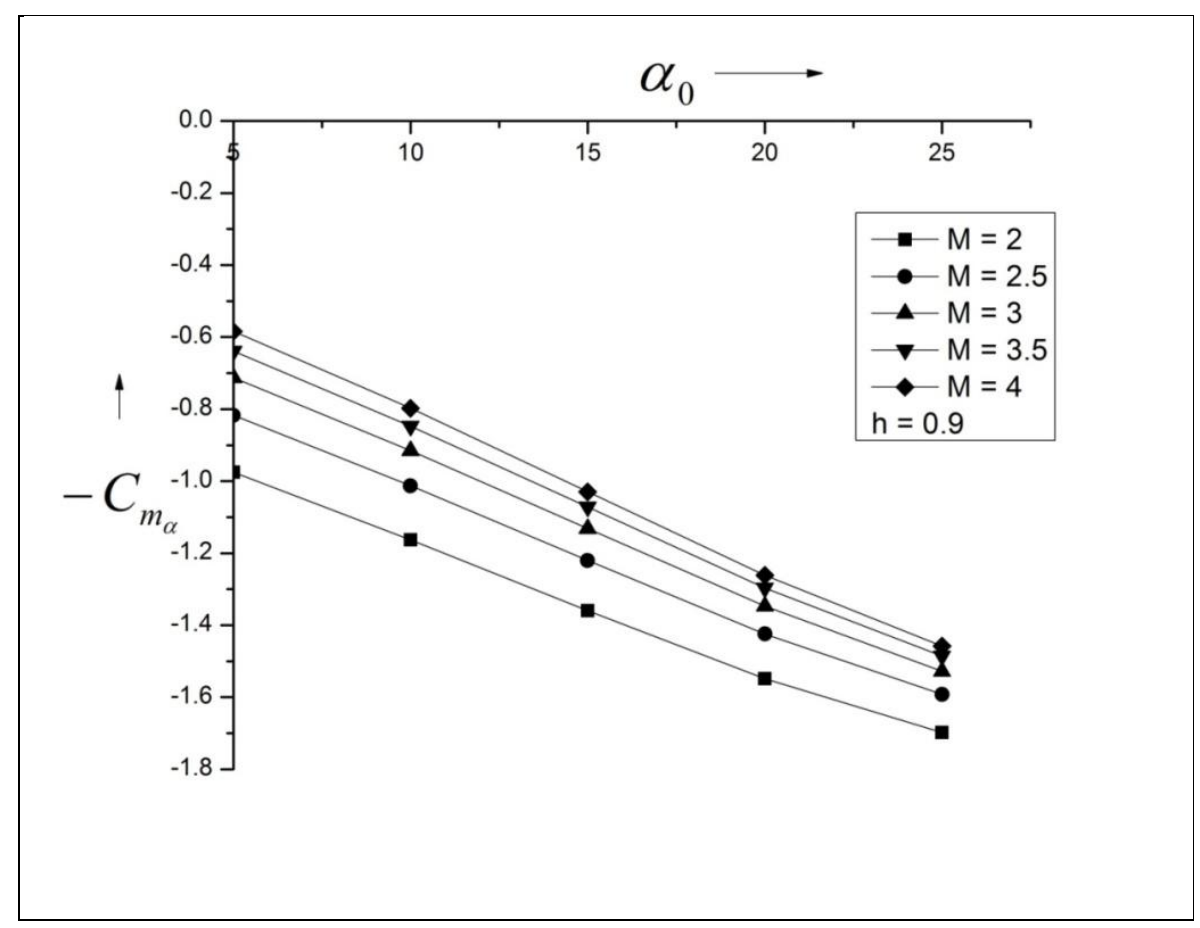

Fig.10: Stiffness derivative versus incidence angle for pivot position $\mathrm{h}=0.9$

Fig.10 shows the Stiffness derivative variation with respect to angle of attack for pivot position $\mathrm{h}=0.9$. It is observed that at the pivot position $90 \%$ away from the nose shows tendency of linear decrement in Stiffness derivative with increase in angle of incidence there is further decrement in the values, however, this decrease is linear. 


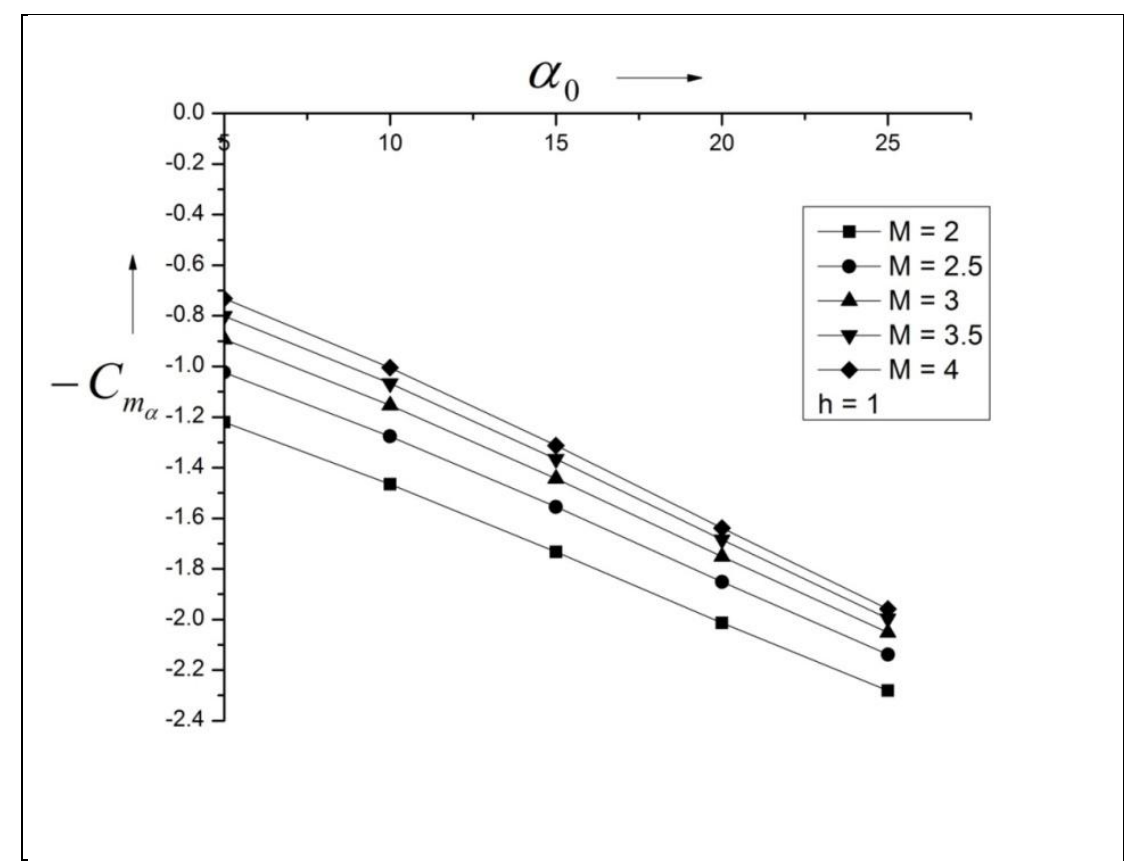

Fig.11: Stiffness derivative versus incidence angle for pivot position $h=1$

Fig.11 shows the Stiffness derivative variation with angle of attack for pivot position $\mathrm{h}=1$. The same trend is same as discused earlier with the exception that magnitude has changed due to change in the location of the pivot position and this pivot position is at the end of the wedge which is the trailing edge and no plan form area is available to counter the nose down moment.

\section{Conclusion}

- From the above discussion it is seen that behaviour of the stiffness derivative for $\mathrm{h}=0,0.1,0.2,0.3$, and 0.4 is on the similar lines which are shown in figures from 1 to 5.

- For $\mathrm{h}=0.5$ the initial values are nearly zero, however due to the increase in the angle of attack there steep rise in the stiffness derivatives.

- For $\mathrm{h}=0.6$ the stiffness derivative has become positive becomes zero for angle of attack 24 degrees and then becomes negative at angle of attack beyond 24 degrees.

- For $\mathrm{h}=0.7$ there is linear decrement the stiffness derivative up to angle of attack 20 degrees and then starts increasing.

- For $\mathrm{h}=0.8,0.9$, and 1.0 there is linear decrement in the stiffness derivative for all the three pivot positions, due to the change in the pivot position there is variation in the magnitude alone.

\section{References}

[1]. Ghosh, K. (1977), "A New Similitude for Aerofoils in Hypersonic Flow”, Proceedings of the $6{ }^{\text {th }}$ Canadian Congress of Applied Mechanics, Vancouver, Canada, May 29-June 3, pp. 685-686.

[2]. Ghosh K.,and Mistry B.K. (1980), "Large incidence Hypersonic Similitude and Oscillating Non-planar Wedges", AIAA Journal, Vol.18, Number 8, Aug. pp. 1004-1006.

[3]. Ghosh, K. (1984), "Hypersonic Large Deflection Similitude for Quasi wedges and Quasi-cones", Aeronautical Journal, March, pp. 70-76.

[4]. Asha Crasta and S. A. Khan, "High Incidence Supersonic similitude for Planar wedge",International Journal of Engineering research and Applications, Vol.2, Issue 5, September-October 2012, pp. 468-471.

[5]. Asha Crasta and S. A. Khan, "Estimation of Stability derivatives of an Oscillating Hypersonic delta wings with curved leading edges”,IJMET, Vol.3, Issue 3, December 2012, pp. 483-492.

[6]. Asha Crasta, M. Ahmed Ali Baig, S. A. Khan , 2012, 'Estimation of Stability derivatives of a Delta wing in Hypersonic flow', International Journal of Emerging trends in Engineering and Developments , Vol. 6, Issue2, Sep., pp. 505-516.

[7]. Asha Crasta and Khan S. A, 2012, 'Oscillating Supersonic delta wing with Straight Leading Edges', International Journal of Computational Engineering Research, Vol. 2, Issue 5, September, pp. 1226-1233.

[8]. Asha Crasta and S. A. Khan " "Determination of Surface Pressure of an axisymmetric ogive in Hypersonic Flow" in Mathematical sciences International Research Journal, Vol. 2, Issue2,August 2013,pp.333-335,ISSN:2278-8697.

[9]. Asha Crasta and S. A. Khan, 2013, 'Stability Derivatives in the Newtonian Limit', International Journal of Advanced Research in Engineering and Technology, Volume 4, Issue 7, Nov-Dec., pp. 276-289.

International Conference on Recent Innovations in Civil \& Mechanical Engineering

[i-CAM2K16] DOI: 10.9790/1684-160530297104 $103 \mid$ Page 
[10]. Asha Crasta and S.A. Khan, 2014, 'Estimation of Stability Derivatives for a Planar Wedge in the Newtonian Limit', IOSR Journal of Mathematics, Volume10, Issue 2 Version I, March-April, pp. 01-06.

[11]. Asha Crasta and S. A. Khan, 2014, 'Effect of Mach number on Stiffness and Damping Derivatives for Oscillating Hypersonic Non-Planar Wedge', IOSR Journal of Mechanical and Civil Engineering, Volume 11, Issue 2 Ver. VIII (Mar- Apr.), pp. 04-11.

[12]. Asha Crasta and S.A. Khan, 2014, 'Effect of Angle of Incidence on Stiffness and Damping derivatives for Oscillating Hypersonic Non-planar Wedge', International Journal for Research in Applied Science and Engineering Technology, Vol. 2, Issue IV, April 2014, pp. 229-242.

[13]. Asha Crasta and S.A. Khan, 2014, 'Supersonic Similitude for Oscillating Non-Planar wedge',IOSR Journal of Mathematics, Volume10, Issue 2 Ver.VI ,Mar-Apr 2014,pp.15-24.

[14]. Asha Crasta and Khan S. A., 2014, 'Stability derivatives of a Delta Wing with Straight leading edge in the Newtonian Limit', International Journal of Engineering research and Applications, Vol. 4, Issue 3, Version 2, March, pp. 32-38.

[15]. Asha Crasta, S. A. Khan , 2014, 'Effect of angle of incidence on Roll damping derivative of a delta Wing', International Journal of Emerging trends in Engineering and Developments Vol. 2, Issue4, March 2014, pp. 343-356.

[16]. Asha Crasta and S.A. Khan, 2014, 'Effect of Angle of Incidence on Stability derivatives of a wing', International Journal for Research in Applied Science and Engineering Technology, Vol. 2, Issue V, May, pp. 411-422.

[17]. Asha Crasta and S. A. Khan, 2014 ,'Effect of Angle of attack on Stability derivatives of a Delta wing with Straight leading edge in Supersonic Flow',International Journal of Mathematics,Vol.10,issue5,Sep-oct 2014. Pp. 01-08.

[18]. Asha Crasta and S. A. Khan, 2014, 'Hypersonic similitude for planar wedges', International Journal of Advanced Research in Engineering and Technology, Volume 5, Issue 2, Feb., pp. 16-31.

[19]. Asha Crasta, S. A. Khan, 2014, 'Effect of sweep angle on Roll damping derivative of a delta Wing', International Journal of Emerging trends in Engineering and Developments Vol15, Issue4, Aug-Sep, pp. 45-55.

[20]. Asha Crasta and S. A. Khan, 2014 ,'Effect of Angle of attack on Stability derivatives of a Delta wing in Hypersonic flow with Straight leading edge',International Journal of Mechanical and civil engineering,Vol.11,issue5,Sep-oct (ver.2). Pp. 21-29.

[21]. Asha Crasta and S.A.Khan 2014," Effect of sweep angle on rolling moment derivative of an oscillating supersonic/hypersonic delta wing”, International journal of modern Engg. Research, Vol.4, issue 10,ver3, pp.15-22.

[22]. Asha Crasta and S. A. Khan 2015, "Effect of Angle of attack on Stiffness derivative of an oscillating supersonic delta wing with curved leading edges" IOSR-JMCE issue1, Volume12, December,pp12-25.

[23]. Asha Crasta and S. A. Khan, "Effect of Angle of attack on Damping derivative of a delta wing with full sine curved leading edges" IJETED Journal issue5, Volume1, December- January 2015.

[24]. Asha Crasta and S. A. Khan,2015 "Estimation of Damping derivative of a delta wing with half sine curved leading edges" IOSR Journal of Mechanical and civil engineering, Vol.12, issue1,February ,pp40-44.

[25]. Asha Crasta and S. A. Khan 2015, "Estimation of Damping derivative in pitch of a Supersonic delta wing with curved leading edges" IOSR Journal of Journal of Mathematics, Vol. 11,issue 1, Jan-feb ,pp.07-15.

[26]. Asha Crasta and S.A.Khan 2015,"Effect of Aspect ratio with angle of attack of an oscillating Hypersonic delta wing with Straight Leading edges", Mathematical Sciences International research Journal",volume 4,issue2, pp.28-33., ISSN2278-8697.

[27]. Asha Crasta and S.A. Khan,2016,"Effect of Aspect ratio with roll moment derivative of a delta wing in supersonic flow", International Journal of Advances in Engineering Research, (IJAER) 2016, Vol. No. 12, Issue No. I, July,pp.10-15, e-ISSN: 2231-5152, p-ISSN: 2454-1796.

[28]. Khan S. A. and Asha Crasta, "Oscillating Supersonic delta wings with curved leading edges",Advanced Studies in Contemporary mathematics, Vol. 20 (2010), No.3, pp. 359-372. 